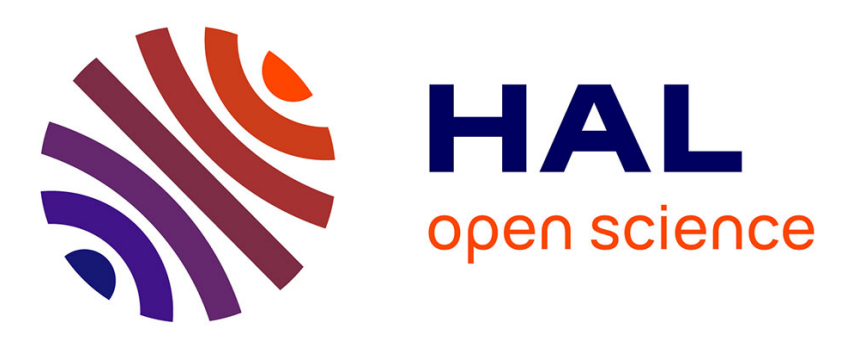

\title{
Attitudinal and socio-structural determinants of cervical cancer screening and HPV vaccination uptake: a quantitative multivariate analysis
}

Kati Kuitto, Susanne Pickel, Henning Neumann, Detlef Jahn, Hans-Robert Metelmann

\section{To cite this version:}

Kati Kuitto, Susanne Pickel, Henning Neumann, Detlef Jahn, Hans-Robert Metelmann. Attitudinal and socio-structural determinants of cervical cancer screening and HPV vaccination uptake: a quantitative multivariate analysis. Journal of Public Health, 2010, 18 (2), pp.179-188. 10.1007/s10389009-0308-z . hal-00535301

\section{HAL Id: hal-00535301 https://hal.science/hal-00535301}

Submitted on 11 Nov 2010

HAL is a multi-disciplinary open access archive for the deposit and dissemination of scientific research documents, whether they are published or not. The documents may come from teaching and research institutions in France or abroad, or from public or private research centers.
L'archive ouverte pluridisciplinaire HAL, est destinée au dépôt et à la diffusion de documents scientifiques de niveau recherche, publiés ou non, émanant des établissements d'enseignement et de recherche français ou étrangers, des laboratoires publics ou privés. 


\title{
Attitudinal and socio-structural determinants of cervical cancer screening and HPV vaccination uptake: a quantitative multivariate analysis
}

\author{
Kati Kuitto • Susanne Pickel • Henning Neumann • \\ Detlef Jahn • Hans-Robert Metelmann
}

Received: 22 February 2009 / Accepted: 24 November 2009/Published online: 5 February 2010

(C) Springer-Verlag 2010

\begin{abstract}
Aim The introduction of the human papillomavirus (HPV) vaccine enables for the first time in the history of cancer prevention the possibility of combating the major cause of a cancer even before its onset. The secondary prevention measure of cervical cancer screening has thus been complemented by a primary prevention measure. The aim of this study is to analyse the determinants of uptake of preventive measures against cervical cancer as a basis for comparing the determinants of screening attendance with those of HPV vaccination attendance.

Subject and methods A population-based representative survey comprising 760 randomly selected women aged 14 to 65 was performed in the German federal state of Mecklenburg-Western Pomerania. Prevention behaviour, attitudes towards cervical cancer screening and HPV vaccination, and knowledge about cervical cancer and HPV were investigated by means of a structured questionnaire. Descriptive analyses and multivariate logistic regression analyses were conducted to identify the determinants of screening and HPV vaccine uptake.

Results Attendance both at screening and at HPV vaccination was best predicted by attitudinal factors. Positive connotations of cancer prevention measures and utility expectations, fear of cancer and high subjective risk perception were conducive to attendance at screening and
\end{abstract}

K. Kuitto $(\bowtie) \cdot$ S. Pickel $\cdot$ H. Neumann $\cdot$ D. Jahn

Department of Political Science, University of Greifswald,

Baderstr. 6/7,

17489 Greifswald, Germany

e-mail: kuitto@uni-greifswald.de

H.-R. Metelmann

Cranio-Maxillo-Facial Surgery, University of Greifswald,

Ferdinand-Sauerbruch-Str. BH 1,

17475 Greifswald, Germany
HPV vaccination. Screening attendance was less regular among women of lower socioeconomic status. In contrast, HPV vaccination uptake was higher for young women with lower educational attainment and lower social class. Knowledge did not impact prevention behaviour significantly. There is no trade-off between screening and vaccination attendance; the vast majority of respondents was aware of the necessity of regular screening attendance even when vaccinated against HPV.

Conclusions Uptake rates for existing primary and secondary prevention measures against cervical cancer can be enhanced by fostering perceptions of utility and positive connotations of regular screening and becoming vaccinated against HPV. Elderly women in particular should be encouraged to attend screening by means of a recall system. Given the low overall level of knowledge about cervical cancer and its risk factors, there is a need for education about the necessity and utility of prevention to reach women of all social classes.

Keywords Cervical cancer prevention - Cervical screening · HPV vaccination $\cdot$ Attitudes $\cdot$ Socio-structural determinants

\section{Introduction}

Since 1971, women in Germany have been entitled to an annual gynaecological examination for early detection of cervical cancer and its preliminary stages. The cervical cancer screening programme is covered by the statutory health insurance for women aged 20 and up, and includes a gynaecological examination and a cytological (Pap) smear. Yet Germany is one of the countries with the highest mortality and incidence rates for cervical cancer in Western Europe (Klug et al. 2005). This might be due to the fact that approximately only 50 percent of women go for regular 
screening (Robra and Dierks 1990; Junge et al. 1992; Schenck and von Karsa 2000; Klug et al. 2005; Marquardt et al. 2007). A longitudinal study on the basis of cytological Pap smear tests in the federal state of Mecklenburg-Western Pomerania shows that more than 50 percent of women with invasive cervical cancer diagnosis had not attended screening in the 5 years preceding the diagnosis, and another 30 percent had attended irregularly (Marquardt et al. 2007). The study impressively demonstrates the link between nonattendance at screening and developing invasive cervical cancer.

Although studies on causes of attendance and nonattendance at screening do exist, very few are based on representative data for women of different ages, and multicausality is not taken into account. Some studies suggest that women of higher socioeconomic status attend screening more regularly than women of lower socioeconomic status (Kahl et al. 1999). The role of fear or anxiety is controversial. While most studies consider fear to be a barrier for screening attendance, others suggest that anxiety is predictive of higher screening attendance (e.g. Consedine et al. 2004 for review of studies on the effects of fear on breast cancer screening). A lack of awareness of risk factors and prevention options is also believed to correlate with lower uptake (Waller et al. 2004; Fylan 1998). Knowledge of cervical cancer and human papillomavirus (HPV) tends to be low overall, as various studies have shown (Baer et al. 2000; Dell et al. 2000; Klug et al. 2005).

Since the autumn of 2006, women have had the option to seek vaccination against HPV. Infection with HPV is the main risk factor for developing cervical cancer and also a sine qua non (Walboomers et al. 1999; Herrero and Munoz 1999). For the first time in the history of cancer prevention, it is now possible to combat cancer and its precursor stages even before its onset. As various HPV types are also a causative factor for several others forms of cancer (oropharyngeal, anal, penile, vulvar and vaginal cancers), the vaccination truly marks a milestone in cancer prevention research (Centers for Disease Control and Prevention 2008; Metelmann et al. 2007a, b). Since March 2007, HPV vaccination against the virus types causing cervical cancer has been officially recommended for girls aged $12-17$ by the Ständige Impfkommision STIKO (German Standing Vaccination Committee). Statutory health insurance providers cover the cost of HPV vaccination for this age group and beyond, in some cases up to the age of 26. As all authorities and professional associations underline, annual screening attendance is necessary despite vaccination because of the residual risk of becoming infected with other potentially carcinogenic HPV types not covered by the vaccine and because of the possibility of having been infected with the high-risk HPV types prior to vaccination (BVF/DGGG 2007).
The availability of vaccination against a causative factor for cervical cancer opens up a multitude of questions and possibilities for an effective prevention strategy. The most crucial issue is to implement the new HPV vaccination in a manner that complements screening in the most effective way. As Hill and Wakefield pointed out in a recent paper, we can identify suitable measures for an effective prevention strategy and benefit from the available primary and secondary prevention measures only if we know which factors help or hinder uptake of cervical cancer prevention measures (Hill and Wakefield 2008).

The study presented in this paper therefore analyses the determinants of cervical cancer screening and HPV vaccination uptake on the basis of a representative survey among 760 women in the German federal state of MecklenburgWestern Pomerania. Our analysis focuses on whether the determinants of screening uptake differ from those of HPV vaccination uptake, identifying and comparing the factors that increase and reduce uptake of these two preventive measures.

\section{Model for explaining uptake of preventive measures}

Health behaviour is a complex psycho-social phenomenon that is influenced by a multitude of factors. Studies in the field of health psychology and medical sociology have developed models for explaining health behaviour overall. Our investigations draw mainly on rationalist models to identify potential key determinants of cervical cancer screening and HPV vaccination uptake. In general, rationalist approaches stress the importance of individual costbenefit calculations related to certain behaviour on the one hand and the appraisal of prevailing social norms and expectations on the other hand. One of the most influential approaches for explaining preventive behaviour is the health belief model developed in the 1950s (Rosenbrock and Michel 2007; Rutter and Quine 2002). The model was developed in response to low uptake rates for screening, and was intended as a means of explaining and predicting uptake of screening and vaccination programmes. Starting from rationalist assumptions, the health belief model stresses the impact of subjective risk perception for a particular disease in terms of perception of the utility of a change in behaviour and existing barriers to the change of behaviour. The importance of subjective risk perception is also stressed by the risk perception and optimistic bias approach (Rutter and Quine 2002). Later, the health belief model was enhanced by the use of demographic factors (age, gender, ethnicity), sociopsychological and socioeconomic variables (personality traits, social class, peer groups) and catalysts for action (prevention campaigns, media reporting and education by medical professionals) 
(Rosenbrock and Michel 2007; Rutter and Quine 2002). Other models, including those based on the theory of planned behaviour (Ajzen 1988) and the theory of social comparison (Festinger 1954), point to the importance of the social component in health behaviour. According to these models, behaviour is strongly related to perceptions of social desirability and acceptance.

Another influential model widely used in studies of health services utilisation, the Andersen behavioural model, suggests that health service utilisation is determined by predisposing factors (socio-demographic variables and health beliefs), enabling factors (personal and societal resources) and need factors (perceived or evaluated illness or impairment-related conditions) (Andersen and Newman 1973; Andersen 1995).

Drawing on these approaches, we developed the model for explaining prevention behaviour shown in Fig. 1. According to our analytical focus, the dependent variable prevention behaviour refers to both cervical cancer screening uptake and HPV vaccination uptake. Socio-structural determinants include age, education, subjectively perceived social class, residential size and setting (urban vs. rural), and distance to gynaecologist. The latter two determinants are of particular potential interest in the context of Mecklenburg-Western Pomerania; the concentration of physicians is low, especially in rural areas, and distances to doctors may be long. Going by previous studies, we would expect screening and vaccination uptake to be lower for older respondents, respondents with low educational attainment and low socioeconomic status. While education and socioeconomic status are strongly correlated, our sample showed only moderate correlation (rho $0.266^{* *}$ ) between these two variables.

Attitudes sum up fear of cancer, attitudes towards health in general (willingness/readiness to engage in healthpromoting behaviour), attitudes towards cancer prevention in general (connotations of the utility of preventive

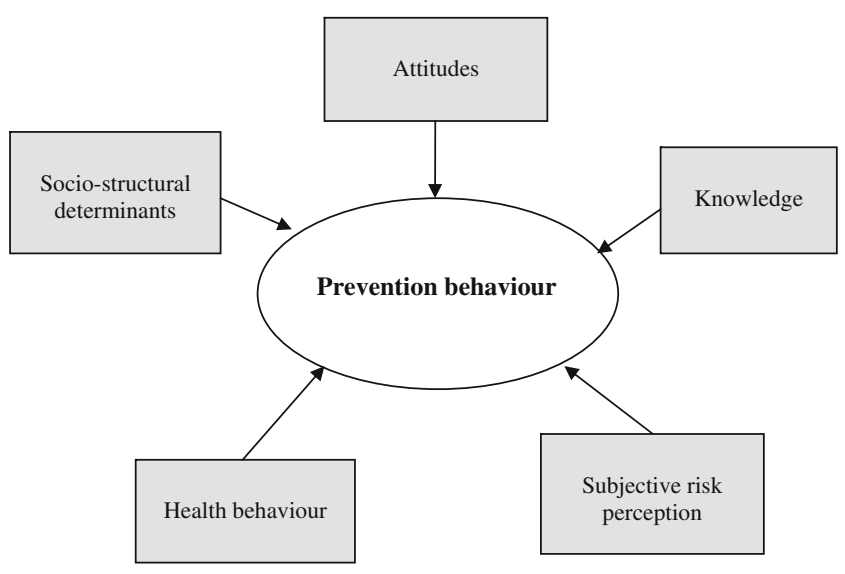

Fig. 1 Theoretical model for explaining prevention behaviour measures and fears associated with attendance) and attitudes towards the preventive measures against cervical cancer (screening and HPV vaccination). For the latter, factor analysis revealed that a question on consideration of screening versus HPV vaccination loaded in three distinct items: "pro HPV vaccination" attitudes (advantages und utility of HPV vaccination), "HPV vaccination scepticism" (sceptical perceptions of the additional value of HPV vaccination for the prevention of cervical cancer) and "pro Pap smear" (advantages and necessity of Pap smear regardless of HPV vaccination). For predicting HPV vaccination uptake, we added attitudes in relation to dissemination of vaccination coverage (HPV vaccination should be offered in schools and/or by local health authorities) and a variable measuring opinions as to who should ultimately be responsible for immunisation protection through vaccination (the state versus the individual). The last variable is of interest in the special context of Mecklenburg-Western Pomerania, which was part of the former German Democratic Republic (GDR). Until 1990, the state offered centralised health services for free, and a widespread immunisation programme was backed by provaccination attitudes among the population. It is of interest to note whether these experiences are associated with greater acceptance of the HPV vaccination in our sample. In general, we would expect positive attitudes towards prevention measures to have a positive impact on prevention behaviour.

Knowledge about cervical cancer, prevention of cervical cancer and - in case of uptake and acceptance of HPV vaccination - knowledge about the HPV vaccination were included in the model as well. Knowledge about the cancer and its prevention is expected to influence the individual cost-benefit calculations for attendance at prevention measures. Informed women are also more likely to have been exposed to statements on the desirability of attending for screening or seeking vaccination, and are thus more likely to be more aware of positively connoted social norms associated with participating in preventive measures. We would thus expect a positive impact of knowledge on prevention behaviour.

Subjective risk perception was identified by asking whether respondents would rate their own risk of developing as likely, unlikely or unthinkable. In accordance with the risk perception and optimistic bias model, we expect respondents to be more likely to attend for preventive measures the higher their subjective risk perception.

Our study also investigates whether screening uptake has an impact on vaccination attendance and vice versa, that is, whether regular screeners are more or less likely to seek vaccination against HPV, or whether women who have been vaccinated against HPV or are going to seek vaccination are neglecting screening. Finally, the study 
looks at whether smoking is associated with more careless prevention behaviour. These three variables account for health behaviour.

\section{Data and methods}

This study is based on representative survey data. Seven hundred sixty randomly selected women aged 14 to 65 living in the German federal state of Mecklenburg-Western Pomerania were interviewed by telephone in February 2008. The data pool included all private households with a telephone connection in Mecklenburg-Western Pomerania. The sample was drawn on the basis of threefold stratified random sample design. The telephone numbers were thereby generated arbitrarily per computer programme and dialled at all times of the day. The women's screening and vaccination behaviour, attitudes towards specific and general heath preventive measures, and knowledge of cervical cancer and of HPV were investigated by means of a structured questionnaire. Socioeconomic characteristics such as education, income and social class were included. The survey was preceded by a pretest with 30 interview partners in order to test the suitability of the questionnaire. The interviewees demonstrated great interest in the topics of the questionnaire - a fact that might be reflected in the very low drop-out rate of 0.9 percent, although the survey included also some rather intimate questions about the respondents' sexual behaviour.

Descriptive statistics with contingency tables and chisquared testing was done to identify differences in uptake rates and attitudes in different age and socioeconomic groups. Causal analysis of the determinants of screening and HPV vaccination uptake was then performed using multivariate logistic regression.

\section{Results}

Uptake of cervical cancer screening and HPV vaccination across age and socioeconomic groups

Distribution of respondents by age group, subjectively evaluated socioeconomic status and educational attainment is shown in Table 1. To investigate screening uptake, respondents were asked "When did you have your last appointment with a gynaecologist for cervical cancer screening including a Pap smear?". Table 1 sums up the rates for regular screening attendance (i.e. within the last 12 months) and for irregular screening attendance (i.e. the last screening took place more than 3 years ago or never). Compared with earlier results for Germany (Schenck and von Karsa 2000) and for the federal state of MecklenburgWestern Pomerania (Marquardt et al. 2007), our sample shows a fairly high rate of women reporting attendance at screening within the recommended interval of 12 months, namely 72.8 percent; 13.1 percent of respondents count as irregular screeners. Chi-squared tests reveal differences in screening attendance rates between different age groups. Young women aged 18 to 35 were significantly more likely to attend for regular screening, while the oldest women in our sample (56-65 years of age) were considerably more likely to report irregular attendance. Of those respondents who said their last screening was 3 or more years ago, 66.3 percent cited good subjective health and 38.1 percent embarrassment as a reason for not attending for gynaecological examination; 27.7 percent said they keep forgetting to make an appointment, and 14.7 percent admitted they were afraid of the possible test results. Screening attendance was also significantly lower among women of lower socioeconomic status; 27.0 percent of respondents who described themselves as working class said they had not attended for screening within the last 3 years or had not ever undergone screening.

Like socioeconomic status, educational attainment also has a significant impact on screening attendance. Women with higher educational attainment tend to attend screening on a more regular basis. This holds true even if we exclude from the analysis respondents under the age of 20, who are more likely to lack educational completion and are not yet eligible for free annual cervical cancer screening.

When it comes to HPV vaccination attendance, the respondents were first asked "Have you already been vaccinated against $H P V$ ?" ("HPV vaccination attendance"). Respondents who answered in the negative were then asked whether they were planning to seek vaccination against HPV in the future ("Intended HPV vaccination attendance"). Both questions are intended to identify individual behaviour with regard to HPV vaccination as a preventive measure. In order to map general approval of vaccination irrespective of the personal utility consideration, respondents were asked whether they would seek HPV vaccination for their daughter. "HPV vaccination approval" in Table 1 indicates the proportion of respondents who said "Yes, I would get my daughter vaccinated whatever the cost". As some previous studies have shown, mothers are broadly in favour of getting their daughters and also their sons vaccinated against HPV (Waller et al. 2006; Slomovitz et al. 2006).

Not surprisingly, rates of actual uptake rate for HPV vaccination as well as vaccination intention are high in the youngest respondent group (age 14-17), but decline rapidly in older age groups. At the time of the survey, 68.0 percent of adolescents aged 14-17 but only 12.7 percent of young women aged 18-26 were already vaccinated against HPV. Rather surprisingly, many older women also said they would consider seeking vaccination against HPV (38.2 percent of women aged 27-35, 30.7 percent of women aged 
Table 1 Socio-economic characteristics of the sample and prevention behaviour

\begin{tabular}{|c|c|c|c|c|c|c|c|c|c|c|c|c|}
\hline & \multicolumn{2}{|c|}{ Sample total } & \multicolumn{2}{|c|}{$\begin{array}{l}\text { Regular } \\
\text { screening } \\
\text { attendance }^{1}\end{array}$} & \multicolumn{2}{|c|}{$\begin{array}{l}\text { Irregular } \\
\text { screening } \\
\text { attendance }^{2}\end{array}$} & \multicolumn{2}{|c|}{$\begin{array}{l}\mathrm{HPV} \\
\text { vaccination } \\
\text { attendance }^{3}\end{array}$} & \multicolumn{2}{|c|}{$\begin{array}{l}\text { Intended HPV } \\
\text { vaccination } \\
\text { attendance }^{4}\end{array}$} & \multicolumn{2}{|c|}{$\begin{array}{l}\text { HPV } \\
\text { vaccination } \\
\text { approval }^{5}\end{array}$} \\
\hline & $\mathrm{N}$ & $\%$ & $\mathrm{~N}$ & $\%$ & $\mathrm{~N}$ & $\%$ & $\mathrm{~N}$ & $\%$ & $\mathrm{~N}$ & $\%$ & $\mathrm{~N}$ & $\%$ \\
\hline Total & 760 & 100.0 & 551 & 72.8 & 99 & 13.1 & 50 & 6.6 & 197 & 31.5 & 506 & 67.5 \\
\hline \multicolumn{13}{|l|}{ Age group } \\
\hline $14-17$ & 50 & 6.6 & 19 & 38.0 & 27 & 55.1 & 34 & 68.0 & 13 & 81.3 & 43 & 86.0 \\
\hline $18-26$ & 118 & 15.5 & 102 & 86.4 & 7 & 6.0 & 15 & 12.7 & 53 & 62.4 & 74 & 62.7 \\
\hline $27-35$ & 102 & 13.4 & 83 & 82.2 & 5 & 5.0 & 1 & 1.0 & 34 & 38.2 & 63 & 62.4 \\
\hline $36-45$ & 201 & 26.5 & 142 & 71.0 & 18 & 9.0 & 1 & 0.5 & 54 & 30.7 & 138 & 69.0 \\
\hline $46-55$ & 144 & 19.0 & 109 & 76.2 & 11 & 7.7 & 0 & - & 26 & 21.1 & 94 & 66.7 \\
\hline $56-65$ & 144 & 19.0 & 95 & 66.4 & 29 & 20.3 & 0 & - & 18 & 13.2 & 94 & 68.1 \\
\hline$X^{2}$ for age group difference $(\mathrm{df}=5)$ & & & \multicolumn{2}{|c|}{$50.31 * * *$} & \multicolumn{2}{|c|}{$101.30^{* * *}$} & \multicolumn{2}{|c|}{$344.36^{* * *}$} & \multicolumn{2}{|c|}{$84.64 * * *$} & \multicolumn{2}{|c|}{$10.53+$} \\
\hline \multicolumn{13}{|l|}{ Social class (subjective) } \\
\hline Underclass & 38 & 5.1 & 21 & 56.8 & 10 & 27.0 & 0 & - & 14 & 38.9 & 22 & 61.1 \\
\hline Lower middle class & 146 & 19.6 & 96 & 65.8 & 20 & 13.7 & 0 & - & 42 & 31.8 & 90 & 61.6 \\
\hline Middle class & 521 & 69.8 & 389 & 75.0 & 64 & 12.4 & 42 & 8.1 & 131 & 31.6 & 353 & 68.9 \\
\hline Upper middle class & 33 & 4.4 & 28 & 84.8 & 4 & 12.1 & 8 & 24.2 & 4 & 16.7 & 29 & 85.3 \\
\hline Upper class & 8 & 1.1 & 5 & 62.5 & 0 & - & 0 & - & 3 & 42.9 & 1 & 14.3 \\
\hline $\mathrm{X}^{2}$ for social class difference $(\mathrm{df}=4)$ & & & \multicolumn{2}{|c|}{$12.43 *$} & \multicolumn{2}{|c|}{$7.78+$} & \multicolumn{2}{|l|}{ n.a. } & \multicolumn{2}{|c|}{3.78} & \multicolumn{2}{|c|}{$17.33^{* *}$} \\
\hline \multicolumn{13}{|l|}{ Education } \\
\hline $\begin{array}{l}\text { No school leaving qualifications/still } \\
\text { at school }\end{array}$ & 58 & 7.7 & 26 & 45.6 & 27 & 47.4 & 37 & 64.9 & 16 & 80.0 & 50 & 87.7 \\
\hline Lower secondary & 56 & 7.4 & 35 & 62.5 & 14 & 25.5 & 0 & - & 15 & 29.4 & 32 & 58.2 \\
\hline Upper secondary & 409 & 54.2 & 310 & 75.8 & 42 & 10.3 & 10 & 2.5 & 112 & 32.2 & 265 & 66.3 \\
\hline Advanced technical certificate & 46 & 6.0 & 31 & 67.4 & 6 & 13.0 & 0 & - & 14 & 34.1 & 33 & 71.7 \\
\hline A-level & 186 & 24.8 & 146 & 78.5 & 10 & 5.4 & 3 & 1.6 & 40 & 24.5 & 123 & 65.4 \\
\hline $\mathrm{X}^{2}$ for social class difference $(\mathrm{df}=4)$ & & & \multicolumn{2}{|c|}{$29.77 * * *$} & \multicolumn{2}{|c|}{$78.56^{* * *}$} & \multicolumn{2}{|c|}{$338.60 * * *$} & \multicolumn{2}{|c|}{$25.72 * * *$} & \multicolumn{2}{|c|}{$13.81^{* *}$} \\
\hline
\end{tabular}

Level of significance: ${ }^{* *} \mathrm{p} \leq 0.001 ; * * \mathrm{p} \leq 0.01 ; * \mathrm{p} \leq 0.05 ;+\mathrm{p} \leq 0.10$

${ }^{1}$ Last screening attendance within the last 12 months

${ }^{2}$ Last screening attendance more than 3 years ago or never

${ }^{3}$ Has been vaccinated against HPV

${ }^{4}$ Intends to get vaccinated against HPV

${ }^{5}$ Would get the daughter vaccinated against HPV in any case

36-45, 21.1 percent of women aged 46-55 and 13.2 percent of women aged 56-65). Differences between age groups are not significant when it comes to approval of HPV vaccination; 86.0 percent of the youngest respondents said they would seek vaccination for their daughter whatever the cost, but the approval rate is also high in the 36-45 and 56-65 age groups.

Unlike screening attendance, HPV vaccination uptake and approval are not as strongly correlated with socioeconomic status. While the professed intention to seek vaccination is higher in lower socioeconomic groups, the differences are not statistically significant, as chi-squared testing shows. In contrast, approval of HPV vaccination is significantly higher in higher socioeconomic groups; 61.1 percent of respondents who described themselves as working class said they would seek HPV vaccination for their daughter, versus the corresponding figure of 85.3 among upper middle class respondents.

With regard to education, the picture is more mixed. Group differences are strongly related to respondents' age, especially in regard to actual or intended HPV vaccination uptake. The highest approval rates for HPV vaccination can be found among respondents without school leaving qualifications/still at school, and again in respondents with intermediate or high educational attainment levels. Again, the differences can also be related to respondents' age, with high levels of approval in the group of respondents without school leaving qualifications/still attending school. 
Results of the multivariate analyses

\section{Model specifications}

Multivariate logistic regression analyses were conducted to test the theoretical model of determinants of screening attendance and HPV vaccination uptake and approval. For models predicting regular (within the last 12 months) and irregular (more than 3 years ago or never) screening attendance, only respondents aged 20 or older were included due to the fact that women are eligible to receive free annual cervical examination including a Pap smear within the framework of the German cervical cancer screening programme starting from the age of 20 (Schenck and von Karsa 2000).

HPV vaccination uptake (already vaccinated/intends to seek vaccination) was analysed among respondents aged 35 or younger. The official recommendation of the Ständige Impfkommission STIKO (German Standing Vaccination Committee) for HPV vaccination applies to adolescent females aged 12 to 17 (RKI 2007), but some health insurance providers cover the cost of vaccination for women up to the age of 26. The best target group for analysis of HPV vaccination attendance within our sample would therefore be respondents aged 14-26, but because of missing data, the number would be too low in this age group alone. Since older women too can benefit from vaccination and since the intention to seek vaccination against HPV is still almost 40 percent in respondents of up to 35 years of age, we extended our analysis on determinants of HPV vaccination uptake to include 14 to 35 year olds (Wright et al. 2008). Finally, the whole sample is included in the model for predicting HPV vaccination approval (would seek vaccination for daughter at whatever cost), since approval of the vaccination should not be solely dependent on considerations of personal utility.

\section{Determinants of screening uptake}

The results of the logistic multivariate regressions are reported in Table 2. Regular screening attendance (Model 1) was best predicted by attitudinal factors, but also by sociostructural characteristics and subjective risk appraisal of the respondents. In contrast, knowledge of cervical cancer or of the prevention measures was not a significant predictor of screening behaviour. Women who said they were afraid of the results of cancer screening were 2.53 times more likely to belong to the regular screening attendance group. Conversely, an absence of fear was predictive of non-attendance, although at a lower level of significance (Model 2). Hence, fear and anxiety seem to encourage rather than hinder regular screening. Fear of a diagnosis of cancer is also related to subjective risk appraisal (rho $0.122 * *$ ), which in turn is a weakly significant predictor for regular screening attendance, and the lack of which is a highly significant predictor for irregular attendance.

Positive connotations of cancer prevention overall (role model effect vis-à-vis children or partner, confidence gains with respect to own state of health through attendance) proved to be another highly influential factor for predicting screening attendance (odds ratio OR 1.77). When it comes to the value of HPV vaccination compared to screening, a pro-Pap smear attitude and utility beliefs were significantly related to regular screening attendance (OR 1.87). Yet respondents who expressed sceptical views about the utility of HPV vaccination were at the same time somewhat less likely to belong to the group of regular screeners (OR 0.73). Hence, it seems more plausible that persons with positive perceptions about the utility of prevention measures, be it screening or vaccination, are more likely to go for screening. There does not seem to be a trade-off between screening and HPV vaccination at the attitudinal level. Nor was uptake of HPV vaccination or approval of the vaccination significantly related to screening behaviour. The non-existence of a trade-off between screening attendance and HPV vaccination is also supported by the fact that 89.5 percent of respondents said they would prefer to take both preventive measures if they had the choice, and 93.9 percent were aware that regular screening is still necessary even after being vaccinated against HPV. On the other hand, respondents who expressed pro-HPV vaccination attitudes were 1.91 times more likely to belong to the group of irregular screening attendants; this effect was weakly significant.

Willingness to engage in health-promoting behaviour such as a healthy diet and regular physical activity was not significantly associated with regular screening attendance, but the lack of it was likely to lead to neglect of regular screening (OR 0.34). Smoking did not have a significant effect.

Contrary to the bivariate relationship reported earlier, education did not have a significant impact on screening behaviour in the multivariate setting. Belonging to a higher social class was significantly associated with more regular screening attendance. Though age was a significant predictor for screening attendance or non-attendance, the odds were very close to one. Against our expectations, living in a rural area and distance to the next gynaecologist did not impact screening attendance, even in a sparsely populated state like Mecklenburg-Western Pomerania.

\section{Determinants of HPV vaccination attendance and approval}

Determinants of HPV vaccination attendance (Model 3) show similarities to those relating to screening behaviour, 
Table 2 Determinants of screening and HPV vaccination attendance and HPV vaccination approval using logistic regressions

\begin{tabular}{|c|c|c|c|c|}
\hline & $\begin{array}{l}\text { Model } 1 \\
\text { Regular screening } \\
\text { attendance }^{1}\end{array}$ & $\begin{array}{l}\text { Model } 2 \\
\text { Irregular screening } \\
\text { attendance }^{2}\end{array}$ & $\begin{array}{l}\text { Model } 3 \\
\text { HPV vaccination } \\
\text { attendance }^{3}\end{array}$ & $\begin{array}{l}\text { Model } 4 \\
\text { HPV vaccination } \\
\text { approval }^{4}\end{array}$ \\
\hline \multicolumn{5}{|l|}{ Sociostructural determinants } \\
\hline Age RC: age group $14-17$ & $0.96 * *$ & $1.06^{* *}$ & $0.87 *$ & 1.01 \\
\hline Education RC: no degree/still at school & 0.84 & 0.85 & $0.56^{* * *}$ & 1.01 \\
\hline Subjective social class RC: underclass & $1.55^{*}$ & $0.62+$ & $0.47+$ & 0.98 \\
\hline Urban residence $\mathrm{RC}$ : rural residence & 1.10 & 1.13 & $7.38 * * *$ & 0.84 \\
\hline Distance to gynaecologist (in minutes) RC: $0 \mathrm{~min}$ & 1.00 & 1.01 & 1.04 & 1.00 \\
\hline Subjective risk perception $\mathrm{RC}$ : no risk perceived & $1.44+$ & $0.46^{* *}$ & $5.29 * * *$ & 1.15 \\
\hline \multicolumn{5}{|l|}{ Knowledge } \\
\hline Knowledge of cervical cancer ${ }^{5}$ & 3.14 & 0.18 & $0.04+$ & $12.24 * *$ \\
\hline Knowledge of prevention of cervical cancer ${ }^{5}$ & 0.95 & 1.14 & $0.04 * *$ & 1.69 \\
\hline Knowledge of HPV vaccination ${ }^{5}$ & & & 0.82 & $5.45^{* *}$ \\
\hline \multicolumn{5}{|l|}{ Attitudes } \\
\hline Fear $^{6}$ & $2.53 * *$ & $0.45+$ & $4.29 *$ & $1.67+$ \\
\hline Positive connotations of cancer prevention measures ${ }^{6}$ & $1.77 * * *$ & $0.40^{* * *}$ & $2.10^{*}$ & 1.13 \\
\hline Willingness to invest in health behaviour ${ }^{6}$ & 1.73 & $0.34 *$ & $5.76^{*}$ & 0.69 \\
\hline Pro HPV vaccination ${ }^{6}$ & 0.77 & $1.91 *$ & 1.73 & 1.00 \\
\hline HPV vaccination scepticism ${ }^{6}$ & $0.73+$ & 1.08 & 0.55 & $0.49 * * *$ \\
\hline Pro Pap smear ${ }^{6}$ & $1.87 * *$ & 0.58 & 0.81 & $1.52+$ \\
\hline $\begin{array}{l}\text { Pro spread of HPV vaccination, e.g., at schools RC: } \\
\text { against spread of vaccination, e.g., at schools }\end{array}$ & - & - & 1.29 & $1.75^{* *}$ \\
\hline $\begin{array}{l}\text { Self-responsibility for immunisation protection RC: } \\
\text { state responsibility }\end{array}$ & - & - & 0.91 & 1.17 \\
\hline \multicolumn{5}{|l|}{ Health behaviour } \\
\hline $\begin{array}{l}\text { Attendance at HPV vaccination RC: non-attendance/does } \\
\text { not intend to }\end{array}$ & 1.16 & 0.53 & - & $2.88 * * *$ \\
\hline $\begin{array}{l}\text { Approval of HPV vaccination RC: would not get } \\
\text { daughter vaccinated }\end{array}$ & 0.70 & 1.29 & $16.55 * * *$ & - \\
\hline Attendance at screening RC: irregular/non-attendance & - & - & 0.36 & 0.71 \\
\hline Smoking RC: does not smoke & 0.98 & 0.49 & 1.45 & $0.55^{*}$ \\
\hline Constant & 0.10 & 56.97 & 0.99 & $0.01 *$ \\
\hline Nagelkerke $\mathrm{R}^{2}$ & 0.188 & 0.301 & 0.617 & 0.293 \\
\hline$N$ & 485 & 485 & 114 & 477 \\
\hline
\end{tabular}

Odds ratios; level of significance: $* * * \mathrm{p} \leq 0.001 ; * * \mathrm{p} \leq 0.01 ; * \mathrm{p} \leq 0.05 ;+\mathrm{p} \leq 0.10$

$\mathrm{RC}=$ reference category

${ }^{1}$ Last screening attendance within the last 12 months; age 20-65

${ }^{2}$ Last screening attendance more than 3 years ago or never; age $20-65$

${ }^{3}$ Has been vaccinated against HPV or intends to seek vaccination; age 14-35

${ }^{4}$ Would have their own daughter vaccinated against HPV whatever the cost, etc.; all respondents

${ }^{5}$ Variables coded dichotomously in $0=$ incorrect knowledge on a given statement $(\mathrm{RC})$ and $1=$ correct knowledge

${ }^{6}$ Variables coded dichotomously in $0=$ does not agree on the given issue $(\mathrm{RC})$ and $1=$ agrees on the given issue

especially with regard to attitudinal factors. Respondents who express fear of screening results (OR 4.29), have positive connotations of cancer prevention measures (OR 2.10) and are willing to invest in their health through appropriate behaviour (OR 5.76) were significantly more likely to seek vaccination against HPV. Subjective risk appraisal was another highly significant predictor of vaccination uptake. Respondents with a heightened awareness of their own risk of getting cervical cancer were 5.29 times more likely to become vaccinated against HPV. However, it is possible that people already vaccinated or who are considering vaccination have had their awareness of the risk of developing cervical cancer raised by a gynaecologist or other physician in connection with the vaccination procedure, or by more in- 
depth engagement with the issue. Thus, we cannot be sure of the direction of the causalities between risk appraisal and vaccination attendance.

The impact of knowledge is somewhat puzzling; while knowledge of HPV vaccination did not have a significant impact on vaccination attendance, knowledge of cervical cancer (OR 0.04) and its prevention (OR 0.04) were associated significantly negatively with HPV vaccination attendance. As the OR shows, the impact is minimal, however.

HPV vaccination attendance was predicted well by sociostructural determinants. Not surprisingly, age was negatively related to uptake of HPV vaccination, although the statistical relevance of age for prediction of vaccination attendance is not very high (OR 0.87$)$. The probability of belonging to the group of actual or potential recipients of HPV vaccination was positively correlated with low educational attainment (OR 0.56) and low socioeconomic status (OR 0.47). Not living in a rural area increased the odds of HPV vaccination uptake by 7.38. Hence, the place of residence was the strongest single predictor in the model apart from approval of HPV vaccination.

Finally, actual uptake of HPV vaccination was very highly associated with approval of HPV vaccination. Since we would expect all rational individuals to show high approval of measures they are willing to undergo, this is hardly surprising. Running the model without approval did not change the results significantly. The $\mathrm{R}^{2}$ for the model was lower (0.536), and sceptical attitudes towards HPV vaccination as well as screening uptake became weakly significant.

Determinants of HPV vaccination approval differ decisively from those of actual vaccination uptake (Model 4). None of the sociostructural factors had a significant impact, but knowledge now became highly significant. Overall knowledge about cervical cancer increased the odds for respondents' willingness to have their own daughter vaccinated against HPV (OR 12.24). Knowledge of HPV vaccination also had a strong positive association with approval of the vaccination.

While fear displayed much lower odds for approval of the vaccination than for the actual prevention behaviour in Models $1-3$, it was still positively associated with approval. Respondents in favour of widespread vaccination, e.g. at schools, were significantly more likely to approve the vaccination (OR 1.75). Logically, subjects attending HPV vaccination themselves were highly likely to approve the vaccination. As was the case for Model 3, running Model 4 without HPV vaccination produced no significant changes. Finally, smokers were less likely to evince strong approval of the vaccination.

\section{Discussion}

This study is one of the first to analyse uptake of cervical cancer screening and HPV vaccination as well as their determinants on the basis of a representative survey of women of a variety of ages. The main results of the study show, first, that self-reported attendance at screening during the 12 months preceding the survey was fairly high in comparison to previous findings in Germany (Schenck and von Karsa 2000; Klug et al. 2005; Marquardt et al. 2007), with more irregular attendance reported by elderly women in particular. Second, screening attendance was significantly higher among respondents of higher socioeconomic status and higher educational attainment. Contrary to this, HPV vaccination reaches also women of lower socioeconomic status and lower educational attainment. HPV vaccination thus does not only reach upper class clientele as some critical voices have claimed. Third, HPV vaccination uptake was high among the primary target group of young women aged 14-17. At the time of the survey, twothirds of women in this age group had been vaccinated against HPV. Among older cohorts, HPV vaccination uptake was radically lower, but a rather large number of respondents even of more advanced ages expressed an intention to seek vaccination. This is somewhat surprising, since the main campaign for the HPV vaccination was targeted mainly at girls and young women, and we cannot expect women to have detailed medical knowledge on the utility of the HPV vaccination for older women (for the utility of the HPV vaccination for women older than 25 years, see e.g. Munos et al. 2009; Harper 2009). Approval rates for HPV vaccination were very high as well. Over two-thirds of all respondents said they would have their daughter vaccinated against HPV irrespective of cost or other factors.

Fourth and most strikingly, the results of the multivariate analyses stress the importance of attitudinal factors for prevention behaviour in general, be it secondary (screening) or primary prevention (vaccination). Positive connotations and utility expectations in relation to prevention measures were important predictors both for screening and HPV vaccination uptake. Willingness to invest in a healthy lifestyle in general was significantly related to HPV vaccination uptake, and the lack of it with irregular screening attendance. According to our results, fear or anxiety boosts rather than hinders uptake. This contradicts the outcome of several earlier studies (Bloom et al. 1987; Austin et al. 2002; Metelmann 2007). Subjective risk perception too is a conducive factor. Knowledge did not impact screening attendance, but ignorance of cervical cancer was weakly related to seeking vaccination against HPV. Yet knowledge was positively associated with approval of HPV vaccination in general. We have to bear in mind, though, that the detailed knowledge of the respondents about cervical cancer, its risk factors and prevention was rather deficient. Thus, the effect of knowledge might rather be based on the awareness that 
attending preventive measures is positive in general than on substantiated knowledge of the cancer and its prevention. For example, it is hard to say whether the elderly women in our sample who report willingness to get vaccinated against HPV themselves are really aware of how and under what circumstances they really can benefit from the HPV vaccination, or whether they just have heard of a vaccination against a cancer and are willing to act for their health by getting vaccinated.

Finally, screening and vaccination attendance did not show evidence of any trade-offs; attending screening regularly was not negatively associated with HPV vaccination uptake, and conversely, vaccination uptake was not significantly related to more irregular screening attendance. Rather, the results suggest that positive attitudes towards prevention measures in general-screening or vaccination is conducive to prevention behaviour. Given the fact that almost all respondents were aware of the advisability of regular screening even after being vaccinated against HPV, it seems there is little cause to worry that HPV vaccination might lead to neglect of screening.

This study has some limitations, though. As the number of respondents in the age group of 14-26 was low, we were not able to conduct detailed multivariate analyses on determinants of uptake of the HPV vaccination and screening in this age group, which would be especially interesting in view of the German recommendations on HPV vaccination practice. For example, all sociostructural factors included in the model explaining vaccination uptake (Model 3 in Table 2) are more interwoven in the subgroup of young women than in the whole sample. We must therefore be cautious in drawing conclusions as to the relevance of sociostructural factors in this age group. Also, more specified indicators of actual knowledge of cervical cancer, risk factors and the mode of operation of the preventive measures would be needed in order to draw conclusions about the relationship of knowledge and prevention behaviour. Further analysis would also be needed on the relationship between knowledge, attitudes toward prevention behaviour and utility expectations.

In conclusion, some important policy implications can be drawn on the basis of the results of this study. The analysis of attendance at screening and HPV vaccination across age, social class and educational features shows that, despite the relatively high rate of yearly uptake of cervical cancer screening, a considerable proportion of women in Mecklenburg-Western Pomerania had missed screening in the year preceding the survey. This is especially true for elderly women, but also for women aged 36-45. Therefore, prevention strategies should seek to encourage regular screening attendance especially among women in age groups unlikely to be consulting their gynaecologist as a matter of course for reproductive or menopausal matters.
Since screening attendance seems to be strongly associated with socioeconomic status, more suitable ways of targeting lower-income women should be developed. Additionally, 27.7 percent of the respondents who had not attended screening for over 3 years said they always forget to make an appointment; a recall system might be helpful.

As a recent global survey of public beliefs and behaviours relevant to cancer reveals, 82.8 percent of respondents in high-income countries are optimistic about possibilities to combat cancer (Hill and Wakefield 2008). The question is, then, how to translate this optimism into individual action and regular utilisation of existing preventive measures. In the case of cervical cancer, more precise information on the necessity of regular screening attendance as well as the utilities of HPV vaccination in different ages should be provided not only by doctors, but also by public authorities. It is essential to sensitise women to the pertinence of screening and HPV vaccination in preventing cancer. Encouraging positive perceptions of attending prevention measures should be accorded more attention in health prevention education.

\section{Source of grant}

This article derives from an ongoing research project for which the research team has received financial grants without any commitments from Sanofi Pasteur MSD.

Acknowledgements The research project from which this article derives is settled within the framework of the multidisciplinary working group Cancer Politics at the University of Greifswald. The authors would like to thank members of the working group for constructive discussions at earlier stages of the project.

Conflict of interest The authors disclose any relevant associations that might pose a conflict of interest.

\section{References}

Ajzen I (1988) Attitudes, personality and behaviour. Open University Press, Milton Keynes

Andersen R (1995) Revisiting the behavioral model and access to medical care: does it matter? J Health Soc Behav 36:1-10

Andersen R, Newman JF (1973) Societal and individual determinants of medical care utilization in the United States. Milbank Meml Fund q, Health Soc 51:95-124

Austin L, Ahmad F, McNally MJ, Steward D (2002) Breast and cervical cancer screening in Hispanic women: a literature review using the health belief model. Women's Health Issues 12:122128

Baer H, Allen S, Braun L (2000) Knowledge of human papillomavirus infection among young adult men and women: implications for health education and research. J Commun Health 25:67-78

Bloom JR, Hayes WA, Saunders F, Flatt C (1987) Cancer awareness and secondary prevention practices in Black Americans: Implications for intervention. Fam Commun Health 10:19-30 
BVF/DGGG (2007) Jährliche Krebsvorsorge trotz erweiterter Früherkennung wichtig. http:/www.frauenaerzte-im-netz.de/ de_news_652_1_210_j-hrliche-krebsvorsorge-trotz-erweiterterfr-herkennung-wichtig.html. Accessed 10 Nov 2008

Centers for Disease Control and Prevention (2008) CDC releases first estimate of human papillomavirus-associated cancer data. Press Release November 32008

Consedine NS, Magai C, Krivoshekova YS, Ryzewicz L, Neugut AI (2004) Fear, anxiety, worry, and breast cancer screening behaviour: a critical review. Cancer Epidemiol Biomarkers Prev 13:501-510

Dell L, Chen H, Ahmad F, Stewart D (2000) Knowledge about human papillomavirus among adolescents. Obstet Gynecol 96:653-656

Festinger L (1954) A theory of social comparison process. Hum Relat 7:117-140

Fylan F (1998) Screening for cervical cancer: a review of women's attitudes, knowledge, and behavior. Br J Gen Pract 48:15091514

Harper DM (2009) Preliminary HPV vaccine results for women older than 25 years. Lancet 373:1921-1922

Herrero R, Munoz N (1999) Human papillomavirus and cancer. Cancer Surv 33:75-97

Hill D, Wakefield M (2008) Understanding and influencing cancerrelated beliefs and behaviour can improve outcome. Lancet Oncol 9:1020-1021

Junge B, Arab-Kohlmeier L, Tiefelsdorf M, Hoffmeister H (1992) Krebsfrüherkennung wird $\mathrm{zu}$ wenig genutzt. Repräsentative Ergebnisse aus dem Nationalen Gesundheits-Survey. Z Allg Med 68:816

Kahl H, Holling H, Kamtsiuris P (1999) Inanspruchnahme von Früherkennungsuntersuchungen und Maßnahmen zur Gesundheitsförderung. Gesundheitswesen 61:163-168

Klug SJ, Hetzer M, Blettner M (2005) Screening for breast and cervical cancer in a large German city: participation, motivation and knowledge of risk factors. Eur J Pub Health 15:70-77

Marquardt K, Broschewitz U et al (2007) Zervixkarzinom trotz Früherkennungsprogramm. Analyse von Teilnahmeraten und Tumorstadium. Frauenarzt 48:1086-1088
Metelmann HR (2007) Umfrage zur Nicht-Nutzung von Krebsprävention. Im Mittelpunkt: Die Angst. Zahnärztliche Mitteilungen 97:128-130

Metelmann HR, Kaduk W, Beier K, Buchstein H, Flessa S (2007a) The impact of cancer politics on oral cancer survival rates. AACR Meeting Abstracts, Apr 2007:LB-139

Metelmann HR, Waite P, Kaduk W (2007b) The overall improvement of out come results in oral cancer appears to be related to early detection. AACR Meeting Abstracts, Dec 2007:A14

RKI (2007) Mitteilung der Ständigen Impfkommission (STIKO) am Robert Koch-Institut: Impfung gegen humane Papillomaviren (HPV) für Mädchen von 12 bis 17 Jahren - Empfehlung und Begründung. Epidemiologisches Bulletin 12:97-103

Robra BP, Dierks ML (1990) Entwicklung der Teilnahme an den Krebsfrüherkennungsuntersuchungen der Frau. Gynäkologe 23:308-311

Rosenbrock R, Michel C (2007) Primäre Prävention. Bausteine für eine Gesundheitssicherung. MWV - Medizinisch Wissenschaftliche Verlagsgesellschaft Berlin, Berlin

Rutter D, Quine L (ed) (2002) Changing health behaviour. Intervention and research with social cognition models. Open University Press, Buckingham, Philadelphia

Schenck U, von Karsa L (2000) Cervical cancer screening in germany. Eur J Cancer 36:2221-2226

Slomovitz BM, Sun CC, Frumovitz M et al (2006) Are women ready for the HPV vaccine? Gynecol Oncol 103:151-154

Walboomers JM, Jacobs MV, Manos MM et al (1999) Human papillomavirus is a necessary cause of invasive cervical cancer worldwide. J Pathol 189:12-19

Waller J, McCaffery K, Wardle J (2004) Beliefs about the risk factors for cervical cancer in a British population sample. Prev Med 38:745-753

Waller J, Marlow LAV, Wardle J (2006) Mother's attitudes towards preventing cervical cancer through human papillomavirus vaccination: a qualitative study. Cancer Epidemiol Biomarkers Prev 15:1257-1261

Wright TC, Huh WK, Monk BJ, Smith JS, Ault K, Herzog TJ (2008) Age considerations when vaccinating against HPV. Gynecol Oncol 109:40-47 